\title{
The Missing Middle \\ Filling the Gap Between Walkability and Observed Walking Behavior
}

\author{
Thomas Herrmann, Geneviève Boisjoly, Nancy A. Ross, \\ and Ahmed M. El-Geneidy
}

\begin{abstract}
Many fields of study recognize the interdependent health, environmental, and economic benefits of walking. To promote walking in entire populations, measures such as Walk Score have been developed to classify the walking friendliness or walkability of places. Yet high walkability is not always equated with increased walking. This paper investigates this discrepancy with the use of survey data on pedestrian behavior; a variety of geographic information system-derived land use and built environment measures of neighborhoods in Montreal, Quebec, Canada; and socioeconomic characteristics obtained from the 2011 National Household Survey. A descriptive analysis of walking behavior and neighborhood characteristics reveals that some neighborhoods with higher walking rates are characterized by a lower presence of parking lots and setbacks and a greater proportion of on-street tree canopy. Linear regressions predicting walking rates confirm these associations after adjusting for Walk Score and neighborhood socioeconomic characteristics. These findings suggest that more work is needed for nuancing walkability measures and offer particular insight for health professionals, planners, and engineers looking to promote walking as an alternative and healthier mode of transport. Reducing open space, such as parking lots and setbacks, and increasing street-level tree canopy are two ways that the urban built environment can be modified to support walking, especially in areas with high Walk Score and low walking rates.
\end{abstract}

Increasing awareness of the environmental, health, and economic benefits of walking has generated interest across disciplines in identifying built environment factors that facilitate walking. These factors are often referred to collectively as "walkability" and include elements related to amenity density (e.g., number of shops or jobs in an area), land use, and street connectivity. Because of the number of factors considered when one attempts to quantify walkability, many researchers have begun developing indexes to capture these elements in a single measure (1). Most existing walkability indexes consider mixed land use, accessibility (i.e., number of destinations reachable on foot), street connectivity, and presence of pedestrian infrastructure as indicators of higher walkability (2). One such index is Walk Score (www.walkscore.com), a proprietary web-based algorithm that

T. Herrmann and N. A. Ross, Department of Geography, and G. Boisjoly and A. M. El-Geneidy, School of Urban Planning, McGill University, Suite 400, 815 Sherbrooke Street West, Montréal, Québec H3A OC2, Canada. Corresponding author: A. M. El-Geneidy, ahmed.elgeneidy@mcgill.ca.

Transportation Research Record: Journal of the Transportation Research Board, No. 2661, 2017, pp. 103-110.

http://dx.doi.org/10.3141/2661-12 assigns a score from 0 (low walkability) to 100 (high walkability) for any address. Walk Score measures street connectivity, population density, and block length, as well as proximity to 13 types of amenities (e.g., grocery stores, restaurants, bars, schools, parks, etc.). A distance decay function assigns weights to these amenities, in which destinations within $0.25 \mathrm{mi}(0.40 \mathrm{~km})$ are assigned full weight and less weight is given to more distant amenities up to $1.5 \mathrm{mi}(2.4 \mathrm{~km})$ (3-5). Walk Score data are easily accessible and thus widely used among researchers $(6,7)$. Although Walk Score makes much of its data available for free on its website, the exact parameters of its index are not public, given the proprietary nature of some of Walk Score's services.

While Walk Score provides an accessible and mostly free resource for researchers to use, it might not fully capture every element of walkability. In Montreal, Quebec, Canada, many areas are found with similar Walk Scores that vary substantially with respect to walking rates. Figure 1 shows the distribution of census tracts' walking rates calculated from survey data, within the same range of Walk Scores using data from Montreal. The distributions reveal that while Walk Score is generally associated positively with walking rates, there is still a high degree of variation in recorded pedestrian activity between census tracts within the Walk Score categories. Given the increasing interest from researchers and policy makers in walkability and walkability indexes, and the discrepancies found between Walk Score and walking rates, the aim of this paper is to identify land use characteristics that are associated with higher rates of walking at the neighborhood level. The paper focuses on identifying walkability factors not included in the Walk Score that might explain the discrepancy between walking rates and Walk Scores. The hypotheses are that $(a)$ parking lots and setbacks will be associated with lower walking rates, while on-street tree canopy cover will be associated with higher walking rates; and $(b)$ Walk Score does not fully account for these neighborhood characteristics. To achieve the research objective, census tracts are identified with a Walk Score and walking rate divergence using a cluster analysis and then the discrepancies in parking lots and setbacks and tree canopy coverage are assessed. Linear regression models then are estimated that predict walking rates as a function of Walk Score, parking lots and setbacks, on-street tree canopy cover, and control variables. Because this study focuses on the influence of the built environment on walking, the authors perform a neighborhood-level analysis as opposed to an individual-level analysis. Accordingly, the findings of this study may be used to improve neighborhood walkability metrics and suggest built environment improvements for increasing walking rate for entire populations. 


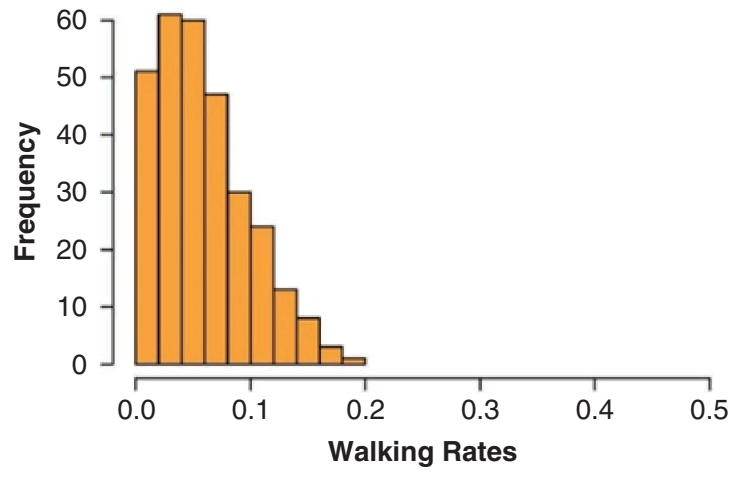

(a)

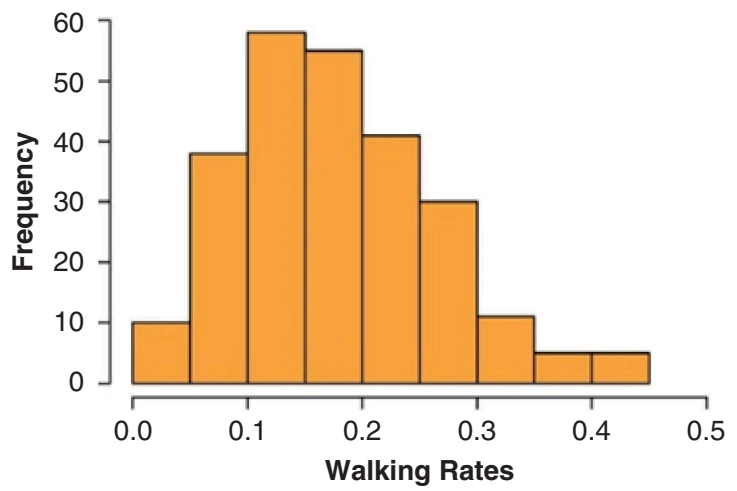

(c)

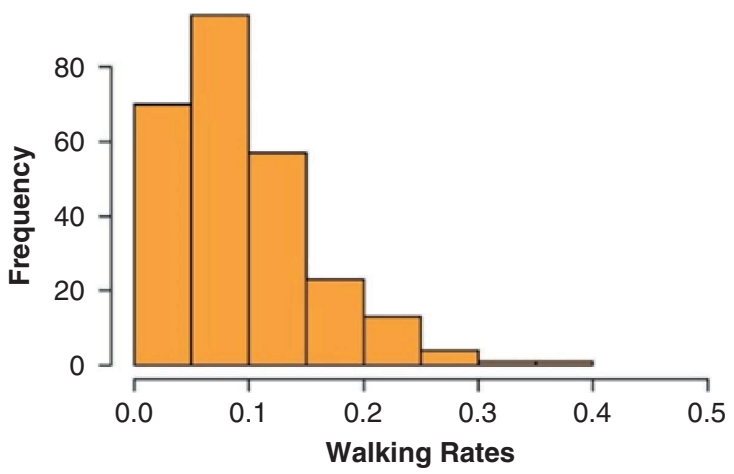

(b)

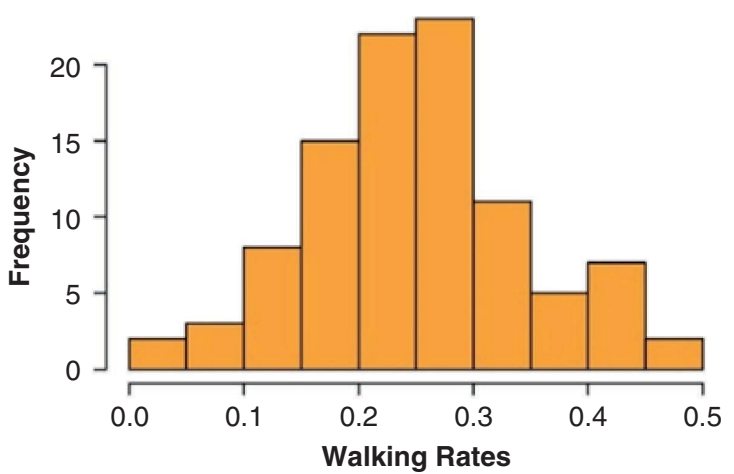

(d)

FIGURE 1 Distribution of walking rates by Walk Score interval in Montreal.

\section{LITERATURE REVIEW AND RESEARCH CONTEXT}

Walking is recognized across several disciplines for its interdependent health, environmental, social, and economic benefits. Starting in the 1990s, health officials in the United States began recommending walking as a form of exercise to combat the onset of chronic illness related to physical inactivity $(8-10)$. While personal characteristics such as age and motivation affect walking frequency and intensity (11), research indicates that certain elements of the built environment influence walking behavior and improve physical health (12). In light of these findings, urban planners now advocate for more compact and less auto-dependent development patterns that facilitate walking (13). Planners cite these walkable compact environments as beneficial not only for health but also for more cost-efficient allocation of transportation infrastructure investments and lower ecological footprints $(14,15)$.

Walk Score is easily accessible and its use in research is now widespread. In health research, for instance, Walk Score has been used to analyze association between obesity (body mass index) and neighborhood built environment $(16,17)$ and to measure walking rates and physical activity levels in socially disadvantaged populations (18). In the field of urban planning, research using Walk Score has been used for policy goals, such as integrating higher-density land uses near transit (19) and simulating travel behavior and carbon footprint impacts of proposed developments (20). While Walk Score has been validated as a general measure of neighborhood walkability $(6,21)$, other research has found gaps in its predictability of walking rates. Koschinsky et al. found that the association between Walk Score and walking is less strong in low-income than in high-income neighborhoods (22). Weinberger and Sweet validate Walk Score as a predictor of walking, but they point out that sensitivity between the Walk Score and walking rates differs by trip type (23). Accordingly, these discrepancies deserve attention and require further investigation in research.

\section{DATA AND METHODOLOGY}

\section{Data}

This study examined the relationship between features of the built environment and walking rates for 466 of 477 census tracts (11 census tracts lacked data) in the city of Montreal. Three types of variables were collected in addition to the Walk Score data: (a) measures of walking behavior, $(b)$ neighborhood characteristics, and $(c)$ neighborhood socioeconomic characteristics. A summarized description of these variables is provided in Table 1.

\section{Walking Rates and Walk Score}

Walking rates were measured as the "pedestrian modal share." These rates are determined from the 2013 Montreal Origin-Destination (O-D) Survey (Table 1). The O-D survey is a phone-based survey conducted once every 5 years during the fall by the Agence Métropolitaine de Transport (AMT) (24). Respondents provide demographic information about their household, characteristics of individual persons taking trips, and disaggregate characteristics of each trip taken 
TABLE 1 Description of Variables

\begin{tabular}{|c|c|c|}
\hline Variable & Description & Source \\
\hline \multicolumn{3}{|l|}{ Walking Behavior Measures } \\
\hline Mean walk trip distance & $\begin{array}{l}\text { Mean distance in meters of all walk trips originating in the census tract assuming } \\
\text { shortest path calculations }\end{array}$ & Montreal O-D Survey (24) \\
\hline Walk-to-work rate & Percentage of all work trips where the primary reported mode is walking & Montreal O-D Survey (24) \\
\hline Walk Score & $\begin{array}{l}\text { Average of all Walk Scores in the census tract }(0-100) \text {, with } 0 \text { indicating } \\
\text { lowest possible walkability and } 100 \text { indicating highest possible walkability }\end{array}$ & Walk Score \\
\hline \multicolumn{3}{|l|}{ Land Use Measures } \\
\hline Parking lots and setbacks & $\begin{array}{l}\text { Proportion of total area characterized by the absence of buildings, water, } \\
\text { or natural environments (e.g., lawns, parking lots, cropland) }\end{array}$ & DMTI Spatial \\
\hline On-street tree canopy cover & $\begin{array}{l}\text { Proportion of the total area of trees within } 10 \mathrm{~m} \text { of the street and the total } \\
\text { area of a buffer of } 10 \mathrm{~m} \text { within the street centerline }\end{array}$ & City of Montreal \\
\hline Paid parking & Binary variable indicating the absence $(0)$ or presence $(1)$ of metered parking & Stationnement de Montréal \\
\hline Distance from highway & Distance in meters from the nearest (grade-separated, limited access) highway & DMTI Spatial \\
\hline \multicolumn{3}{|l|}{ Controls: Sociodemographic } \\
\hline Median household income & Median household income reported in 2010 & $\begin{array}{l}\text { Statistics Canada (National } \\
\text { Household Survey 2011) }\end{array}$ \\
\hline Percentage immigrant & $\begin{array}{l}\text { Percentage of neighborhood population that is an immigrant to Canada } \\
\text { (i.e., not Canadian born) }\end{array}$ & $\begin{array}{r}\text { Statistics Canada (National } \\
\text { Household Survey 2011) }\end{array}$ \\
\hline
\end{tabular}

by individuals during the previous day. Trip information, including trip mode, purpose, origin, and destination, is collected for $5 \%$ of households in the metropolitan area and this study's analyses are based on home-based trips for 51,547 adults (ages 18-65) (25). For this analysis, any trip where both the origin and destination were reached by walking was considered a pedestrian trip. The walking rate, therefore, reflects the percentage of all trips that were pedestrian trips. A walk-to-work rate was also calculated by finding the percentage of all trips made for commuting to work that were pedestrian trips. The shortest path walking distance for all pedestrian trips was calculated in a geographic information system using a pedestrian street network (i.e., one with highways removed and on-street paths included). Using expansion factors provided by the AMT, the data are aggregated to the census tract level to calculate the walking rates. While many studies examine walkability by using trip origin or destination coordinates $(4,26)$, other studies have used Walk Score at a similar neighborhood level of analysis $(22,27)$.

The Walk Score is a continuous variable between 0 (lowest possible walkability) and 100 (highest possible walkability). Walk Scores were downloaded at the postal code level. In Canada, postal codes are smaller than census tracts: approximately the size of one side of a city block. The 39,648 Walk Scores for each postal code were aggregated to the 466 census tracts by determining the centroid of each postal code and averaging Walk Score values for postal code centroids within each census tract. The average number of points aggregated to the census tract level was 78. The average standard deviation for Walk Score points within census tracts was 4.90 .

\section{Land Use Measures: Parking Lots, Setbacks, and Tree Canopy}

Parking lots and setbacks were determined with clutter data from DMTI Spatial, Inc. (28). The clutter data consist of raster data sets at a 30-m resolution and 10 values representing different land use classifications. Most of the land uses are based on data from the National Topographic Database, which is itself a database of delineations of different terrains, forest cover, populated places, and industrial infrastructure collected by Natural Resources Canada at the 1:50,000 scale. "Open land" is one of 10 land use classifications included in the clutter data. Open land refers to areas where the National Topographic Database has no mapped features. These areas contain neither natural terrains (e.g., rivers, lakes, forest, wetlands, etc.) nor built features (e.g., buildings, pipelines, dams, etc.). Satellite imagery reveals that most open land uses in urban settings are humanmanipulated areas, such as parking lots and other forms of setbacks, such as driveways and lawns. The clutter data do not classify parks as open space. A neighborhood with a large park, therefore, will not necessarily have a large proportion of open space, but a neighborhood with more space between buildings will have more open space. The percentage of each census tract's parking lots and setbacks is calculated by converting the raster pixels to vector centroids in a geographic information system and calculating the percentage of open land centroids as a total of all land class centroids for each census tract. It is expected that open land use (parking lots and setbacks) will depress walking rates, because parking lots and setbacks reduce dwelling densities.

On-street tree canopy cover is assessed from a shapefile containing polygon features of each tree in the city of Montreal, which was downloaded from the city's website (29). The tree canopy shapefile was created by the city in 2007 and made available online in 2013. A central assumption of using the tree canopy data is that only trees near streets will correlate positively with walking rates. Only trees with a majority of their area within $10 \mathrm{~m}$ of the street centerline were included. This assumption is consistent with research that suggests that on-street trees provide a more favorable walking environment (30). This on-street tree canopy variable represents the percentage of the area of the 10-m street buffer that is covered by the tree canopy 
in each census tract. The average census tract in Montreal has an $18.98 \%$ tree cover surrounding its streets, with a standard deviation of 11.06 across the sample.

\section{Auto Dependency Controls: Paid Parking and Distance from Highway}

Two variables measured auto dependency: the presence of on-street metered parking (paid parking) in the census tract and distance from the centroid of the census tract to the nearest limited-access highway. The geocoded location of parking meters was taken from the Stationnement de Montréal (local parking authority) website. It was expected that paid parking would be positively associated with walking rates because paid parking is generally implemented in areas with lower car ownership (3), whereas free parking is associated with higher rates of automobile-oriented investment and use (31). The distance from a highway variable is calculated by measuring the distance in meters between the centroid of the census tract and the nearest highway segment using shapefiles provided by DMTI Spatial, Inc. Distance from highway is expected to be positively associated with walking rates, because highways often represent physical barriers in the environment that correlate with lower walking rates (32).

\section{Sociodemographic Controls: Median Household Income and Percentage of Immigrants}

The sociodemographic profile of the census tracts is thought to influence walking behavior (33). Median household income and the percentage of immigrants (i.e., people who immigrated to Canada at any time) were calculated for each census tract from 2011 National Household Survey data. In Canada, major urban centers host substantial immigrant populations whose travel behaviors may differ from those of Canadian-born individuals. In the Montreal Census Metropolitan Area (CMA), for instance, $48.6 \%$ of recent immigrants commuted to work by public transit compared with $20.9 \%$ of Canadian-born commuters (34).

\section{Methodology}

Acluster analysis ( $k$-means approach) was performed to identify census tracts with a Walk Score and walking rate divergence. A descriptive analysis then compared walking behavior (walking rate, walk-towork rate, and average walk trip distance) and neighborhood characteristics (Walk Score, median household income, parking lots and setbacks, on-street canopy cover, and population density) between the different clusters.

Three linear regression models of walking rates were estimated. Each of the three models uses walking rate as the independent variable, four control variables (paid parking, distance from highway, median household income, and percentage of immigrant population), and different sets of predictor variables. The first model considers the relationship between walking rate and the land use measures of interest (parking lots and setbacks and the on-street tree canopy), while the second model examines the relationship between the pedestrian modal share and Walk Score. The third model uses both Walk Score and the land use measures of interest (parking lots and setbacks and the on-street tree canopy) as independent variables. The work- ing assumption is that these two variables will remain significant when one adjusts for Walk Score.

Independent variables were tested for multicollinearity in each regression model. The multicollinearity between each independent variable and the dependent variable was determined by finding the variable inflation factor (VIF). The highest VIF found of any independent variable in any model was 2.290 (Walk Score). Walk Score was the only variable that had a VIF above 2 . Often, variables are eliminated on the basis of multicollinearity if the VIF exceeds 10 (35). The VIFs of this study's independent variables were well below this common threshold.

\section{RESULTS AND ANALYSIS}

\section{Cluster Analysis}

Six clusters displayed the least redundancy and most variation across groups (Figure 2). Clusters 1 and 2 had above-average (high) Walk Scores (HWS), Clusters 3 and 4 had average Walk Scores (AWS), and Clusters 5 and 6 had below-average (low) Walk Scores (LWS), when compared with the citywide sample. Clusters 1 and 2 had aboveaverage Walk Scores but Cluster 2 exhibited a much lower walking rate, only slightly above the average. With respect to Clusters 3 and 4, with average Walk Scores, Cluster 3 had an above-average walking rate, whereas Cluster 4 had a below-average rate.

Walk Scores and walking rates gradually decrease away from the central area of the city (Figure 3). The distinct colors represent different Walk Score pairs: Clusters 1 and 2 (blue) with high Walk Scores, Clusters 3 and 4 (orange) with average Walk Scores, and Clusters 5 and 6 (gray) with low Walk Scores. Each shade signifies where the walking rates are higher or lower than the other cluster within that pair, revealing the variation between census tracts within the same Walk Score classification and in similar geographic locations.

Despite their comparable Walk Scores (75 and 76), the walking rate of Cluster $3(23 \%)$ was nearly double that of Cluster $4(12 \%)$ (Table 2). The walk-to-work rate of both clusters was the same (6\%), suggesting that noncommuting trips (such as shopping trips, trips to visit a friend, etc.) are driving higher walking rates in Cluster 3. These groups are very similar socioeconomically, suggesting that elements of the built environment, and not personal or socioeconomic characteristics, are influencing the difference in walking behavior between these clusters. Similar patterns were observed in the HWS pair (Clusters 1 and 2). Despite similar Walk Scores (90 and 91), walking rates were much higher in Cluster $1(35 \%)$ than in Cluster 2 $(20 \%)$. As in the AWS cluster, the socioeconomics and walk-to-work rates of Clusters 1 and 2 were similar.

Descriptive statistics reveal that the land use characteristics of interest in higher walking rate clusters follow the expected direction. For HWS and AWS cluster pairs, the cluster with the lowest walking rate also has the highest proportion of parking lots and setbacks. In Cluster 3, the proportion of land used devoted to parking lots and setbacks (14\%) is lower than in Cluster $4(26 \%)$. Conversely, in the same pair, the cluster with the highest walking rate has the highest on-street canopy cover: Cluster 3 has a larger proportion of land as on-street tree canopy (26\%) than Cluster 4 (20\%). In the HWS pair, the cluster group with more walking also follows the expected pattern: there are fewer parking lots and setbacks (6\% versus $14 \%)$ and more trees (28\% versus $22 \%$ ) in Cluster 1, where walking rates are $35 \%$, compared with Cluster 2, where walking rates are $20 \%$. 


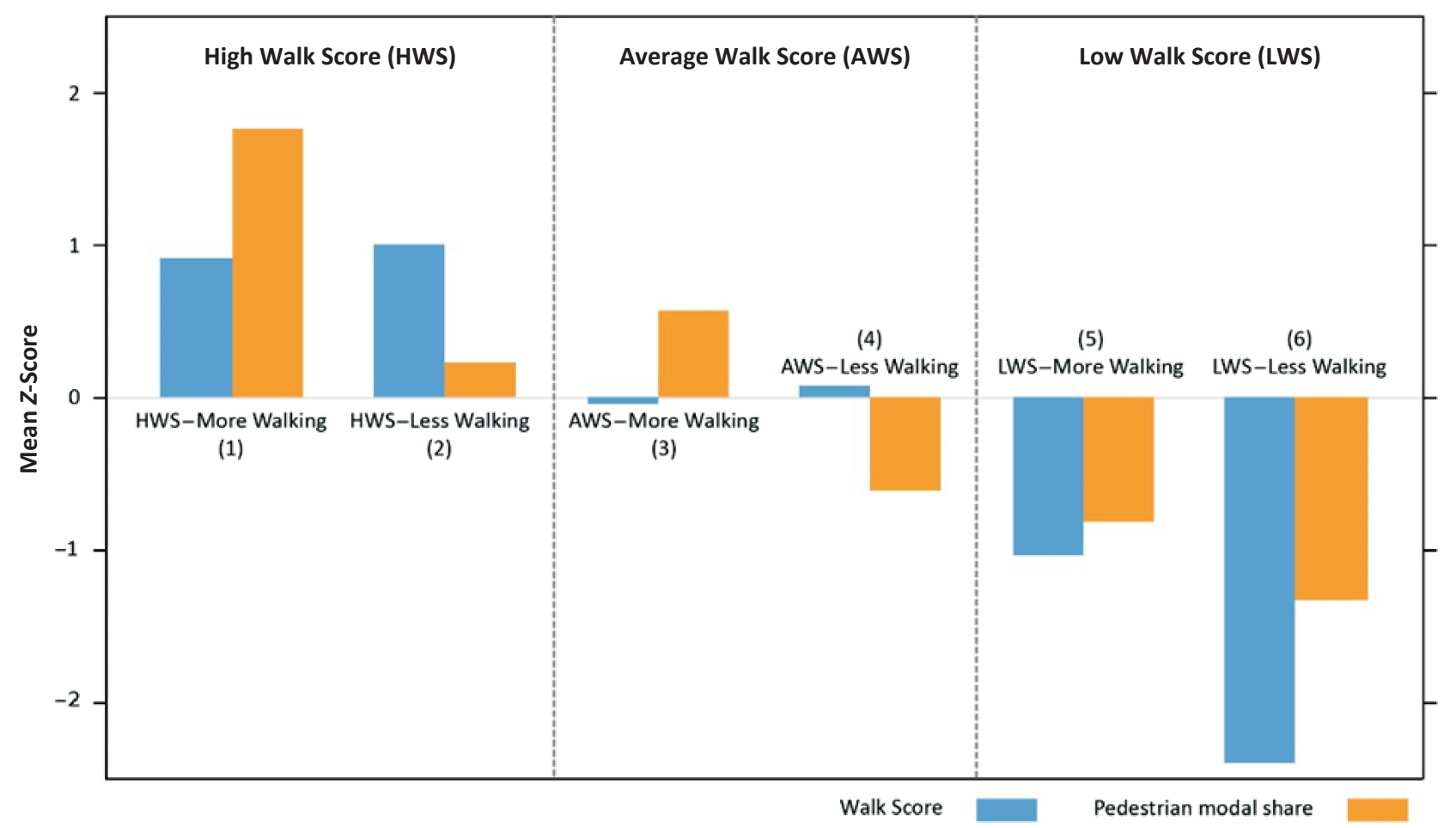

FIGURE 2 Cluster analysis of Montreal census tracts $(n=466)$ with the use of Walk Score and walking rate.

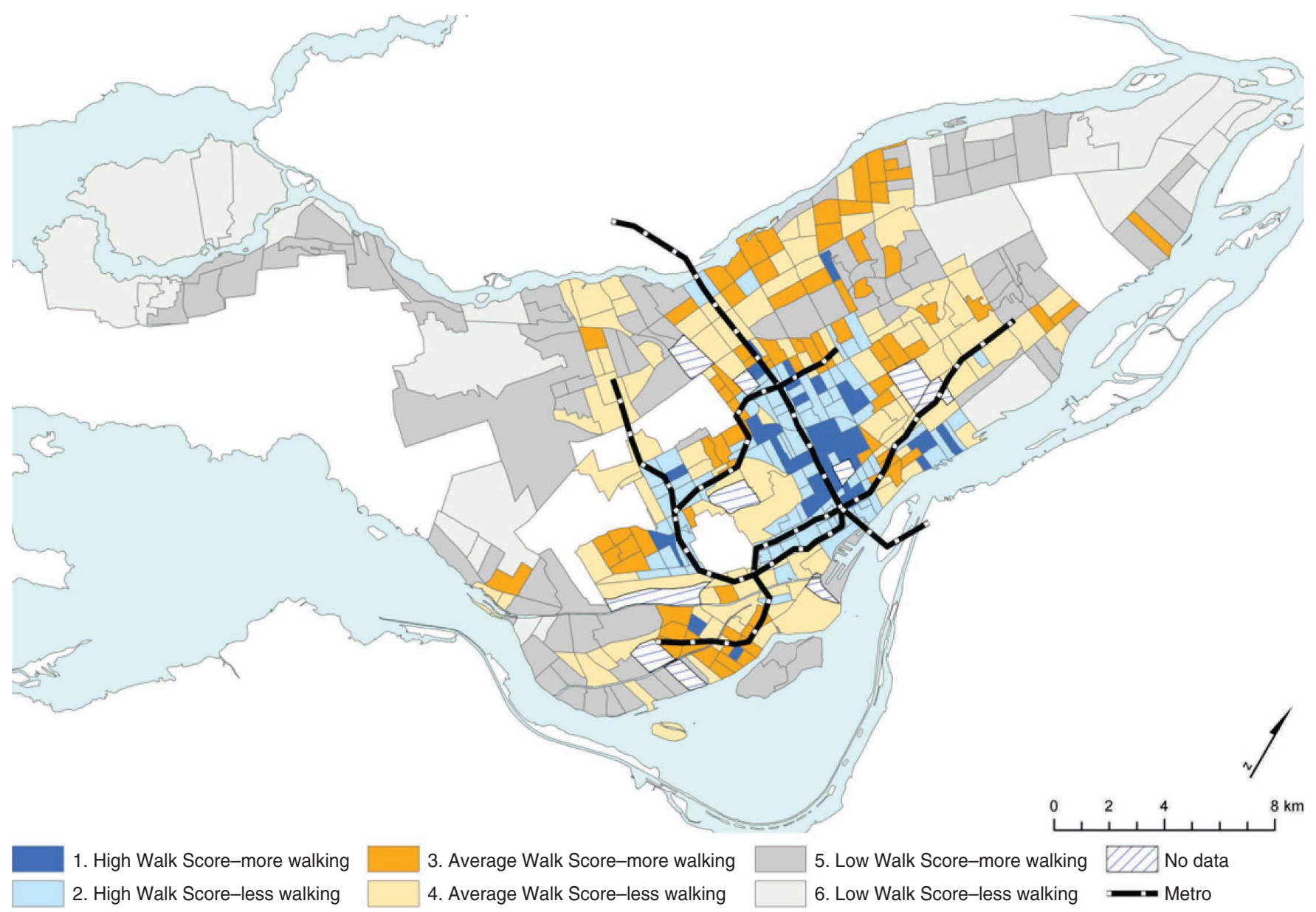

FIGURE 3 Geographic distribution of clusters of Walk Score and walking, Montreal census tracts $(24,28$ ). 
TABLE 2 Descriptive Statistics of Six Clusters

\begin{tabular}{|c|c|c|c|c|c|c|}
\hline \multirow[b]{2}{*}{ Variable } & \multicolumn{2}{|c|}{ High Walk Score } & \multicolumn{2}{|c|}{ Average Walk Score } & \multicolumn{2}{|c|}{ Low Walk Score } \\
\hline & $\begin{array}{l}\text { High Walking } \\
\text { Cluster } 1\end{array}$ & $\begin{array}{l}\text { Low Walking } \\
\text { Cluster } 2\end{array}$ & $\begin{array}{l}\text { High Walking } \\
\text { Cluster } 3\end{array}$ & $\begin{array}{l}\text { Low Walking } \\
\text { Cluster } 4\end{array}$ & $\begin{array}{l}\text { High Walking } \\
\text { Cluster } 5\end{array}$ & $\begin{array}{l}\text { Low Walking } \\
\text { Cluster } 6\end{array}$ \\
\hline Sample size & 63 & 96 & 79 & 110 & 91 & 27 \\
\hline Walk Score $(0-100)$ & 90.02 & 91.34 & 74.84 & 76.45 & 58.88 & 37.06 \\
\hline Median household income (\$) & 43,493 & 41,068 & 42,245 & 42,107 & 54,586 & 67,763 \\
\hline Parking lots and setbacks, average $(\%)$ & 6 & 14 & 14 & 26 & 28 & 41 \\
\hline On-street canopy cover, average (\%) & 28 & 22 & 26 & 20 & 15 & 15 \\
\hline Walking rate $(\%)$ & 35 & 20 & 23 & 12 & 10 & 5 \\
\hline Walk-to-work rate $(\%)$ & 17 & 15 & 6 & 6 & 4 & 2 \\
\hline Population density (per $\mathrm{km}^{2}$ ) & 14,020 & 10,616 & 9,895 & 7,751 & 5,319 & 2,548 \\
\hline Average walk trip distance (m) & 856 & 942 & 813 & 1,019 & 975 & 1116 \\
\hline
\end{tabular}

\section{Regression Models}

The results of the regression models are reported in Table 3. The first model explains $46.1 \%$ of the variation in walking rate, with parking lots and setbacks driving the model strongly; for each $10 \%$ increase in the proportion of parking lots and setbacks, a 1.7\% decrease in walking rate is expected (Table 3 ). Conversely, the presence of a larger on-street tree canopy is shown to be positively associated with walking rates; for each $10 \%$ increase in tree canopy, a $0.7 \%$ increase in the walking rate is predicted. Model 2 examines the relationship between walking rates and Walk Scores. The Walk Score term is significant and positively associated with walking rates, and the model explains a similar amount of variation in walking rates $\left(R^{2}=44.1 \%\right)$ as Model 1. When Walk Score, parking lots and setbacks, and tree canopy are modeled together in Model 3, the model fit $\left(R^{2}=50.4 \%\right)$ is better compared with Models 1 and 2. The comparative assessment of Model 1 and Model 3 reveals that the proportion of parking lots and setbacks and on-street canopy remains significant when Walk Score is included in the model. Also, including the new land use variables (parking lots and setbacks and on-street tree canopy), in addition to the Walk Score variable, increases the explanatory power of the model.
With respect to the other explanatory variables, presence of paid parking and distance to highway are positively associated with walking rates in all models, as expected. The paid parking variable, in particular, is highly predictive of walking rates. For example, in Model 1, walking rates are found to be $6 \%$ higher in the census tracts with paid parking versus those without it. Finally, census tracts with higher proportions of immigrants and higher median incomes are negatively associated with walking rates in all three models.

\section{DISCUSSION OF RESULTS}

Neighborhoods with similar levels of walkability may "produce" different levels of walking rates in their populations. The cluster analysis confirms the preliminary findings that there is considerable variation in walking rates among census tracts with similar Walk Scores. The study found three pairs of cluster groups with similar Walk Scores and similar socioeconomics, but substantial differences between the groups within the pairs in walking rates and land uses. The descriptive statistics associated with each cluster group highlight that in the higher walking rate clusters, the presence of parking lots and setbacks is lower, whereas the proportion of on-street tree

TABLE 3 Regression Coefficients Predicting Walking Rate at Census Tract Level

\begin{tabular}{|c|c|c|c|c|c|c|c|c|c|}
\hline \multirow[b]{3}{*}{ Variable } & \multicolumn{3}{|l|}{ Model 1} & \multicolumn{3}{|l|}{ Model 2} & \multicolumn{3}{|l|}{ Model 3} \\
\hline & \multirow[b]{2}{*}{ Coefficient } & \multicolumn{2}{|l|}{ CI } & \multirow[b]{2}{*}{ Coefficient } & \multicolumn{2}{|l|}{$\mathrm{CI}$} & \multirow[b]{2}{*}{ Coefficient } & \multicolumn{2}{|l|}{$\mathrm{CI}$} \\
\hline & & Lower & Upper & & Lower & Upper & & Lower & Upper \\
\hline Constant & $0.250 * *$ & 0.219 & 0.280 & -0.015 & -0.071 & 0.042 & $0.083^{* *}$ & 0.023 & 0.142 \\
\hline Walk Score & - & - & - & $0.003^{* *}$ & 0.002 & 0.003 & $0.002 * *$ & 0.001 & 0.002 \\
\hline Parking lots and setbacks & $-0.169 * *$ & -0.209 & -0.129 & - & - & - & $-0.130 * *$ & -0.171 & -0.090 \\
\hline On-street tree canopy & $0.073 * *$ & 0.032 & 0.114 & - & - & - & $0.057 * *$ & 0.017 & 0.096 \\
\hline Paid parking & $0.062 * *$ & 0.047 & 0.076 & $0.035^{* *}$ & 0.017 & 0.052 & $0.031 * *$ & 0.015 & 0.048 \\
\hline Distance from highway & $0.010 * *$ & 0.004 & 0.017 & $0.016^{* *}$ & 0.009 & 0.023 & $0.011 * *$ & 0.005 & 0.018 \\
\hline $\begin{array}{l}\text { Median household income } \\
\text { (tens of thousands) }\end{array}$ & $-0.014 * *$ & -0.018 & -0.010 & $-0.005^{*}$ & -0.010 & -0.001 & $-0.008 * *$ & -0.012 & 0.003 \\
\hline Immigrant percentage & $-0.100^{* *}$ & -0.148 & -0.052 & $0.092 * *$ & -0.141 & -0.044 & $-0.098 * *$ & -0.144 & -0.052 \\
\hline
\end{tabular}

Note: $\mathrm{CI}=$ confidence interval; $-=$ not used in model; $n=466$.

$R^{2}$ : Model $1=.461 ;$ Model $2=.441 ;$ Model $3=.504$.

$* p<.05 ; * * p<.01 ; * * * p<.001$. 
canopy is greater, as hypothesized. These associations follow both within and between each cluster pair.

The regression models validate the trends observed in this cluster and descriptive statistics analysis after adjustment for neighborhood socioeconomic characteristics. The presence of parking lots and setbacks was found to be negatively associated with walking rates, even when controlling with Walk Scores. Conversely, the presence of an abundant on-street tree canopy was found to be associated favorably with walking rates in neighborhoods, over and above the influence of the overall walkability of a neighborhood as measured by the Walk Score.

The finding on the relationship between walking rates and the presence of parking lots and setbacks is complementary with many conventional measures of walkability. Since the presence of parking lots and setbacks denotes the absence of buildings, it is reasonable to assume that areas with higher amounts of parking lots and setbacks will also have lower dwelling densities. As low dwelling densities decrease local accessibility of destinations and the presence of parking lots increases access to destinations by car (36), areas with more parking lots and setbacks simultaneously discourage walking trips and incentivize car travel. Parking lots and setbacks may also impede street connectivity, especially in urban areas where they are associated with larger industrial footprints (37). Areas with large industrial setbacks have also been found to increase pedestrian crash frequency (38), which could discourage walking. While some of these effects are accounted for by Walk Score or similar walkability measures, this study highlights that they are not fully captured by Walk Score.

It was also found that census tracts with a larger street tree canopy had higher rates of walking, independent of Walk Score. This finding contradicts a similar study conducted in the Twin Cities (Minneapolis and Saint Paul, Minnesota), which did not find a significant difference between the presence of trees and walking rates for transport (39). Nevertheless, the positive influence of the street tree canopy on walking can be attributed to a more aesthetically pleasing walking experience $(40,41)$. The street tree canopy also influences the comfort of walking in warmer weather by providing shade and cooling from evapotranspiration $(42,43)$. These effects may encourage walking, as opposed to areas with less trees but more parking lots and setbacks.

\section{STUDY LIMITATIONS}

First, while the Walk Score values used in this analysis are relatively recent (2013), Walk Score has since changed its methodology. Beginning in 2014, Walk Score began using street network buffers to derive neighborhood walkability measures; the older Walk Score values used for this analysis used Euclidean distance buffers instead (4). Accordingly, this study's models may slightly underestimate the association between Walk Score and walking rates. Within the scope of this study, it was not feasible to obtain more recent Walk Score values at the level of analysis desired. Nonetheless, the findings identify environmental and land use factors with strong associations to walking rates that have never been used by Walk Score.

Second, given the methodology used by the AMT for the 2013 Montreal Origin-Destination Survey, the authors cannot guarantee that all walking trips that occur in the Montreal CMA were surveyed evenly at the level of analysis (census tracts). Nonetheless, each census tract contains at least 30 trips of any travel mode, and the sample size of the survey (5\% of households in the Montreal CMA) is substantial.
Third, because of the neighborhood level of this analysis, the results of this analysis are subject to some generalization and smoothing, especially as some data were aggregated at the census tract level. The effects of these externalities are mitigated by using the smallest aggregation geography available (census tract). The analysis is intended to understand broad patterns of walking behavior at the population level and not determinants of an individual's walking behavior.

\section{CONCLUSION}

This paper examined areas where the strength of association between Walk Score and walking rates was less strong than expected. The cluster analysis reveals substantially different walking rates between clusters with similar Walk Score means. On the basis of the findings in the regression analysis, the authors can confirm that consideration of parking lots and setbacks and on-street tree canopies would improve the predictive power of Walk Score. In areas where the association between Walk Score and walking rates diverged, this finding is often explained by the presence of parking lots and setbacks and absence of trees, as these areas neither increase amenity density (as buildings do) nor improve the aesthetics or comfort of the pedestrian environment (as trees do). Therefore, it is important for researchers to consider this balance between neighborhood land use and greenness when using, interpreting, and designing walkability metrics.

\section{ACKNOWLEDGMENTS}

The authors thank the anonymous reviewers for their feedback on the earlier version of the manuscript. The authors gratefully acknowledge the Agence Métropolitaine de Transport (AMT) for providing the detailed 2013 Origin-Destination Survey data that enabled this study and particularly Gabriel Sicotte for his feedback. This research was funded by the Natural Science and Engineering Research Council of Canada and the Social Sciences and Humanities Research Council of Canada. Last but not least, the authors thank Lesley Fordham, Emily Grisé, Dea van Lierop, and Derrick Swallow of Transportation Research at McGill University for their support and feedback.

\section{REFERENCES}

1. Frank, L. D., J.F. Sallis, B. E. Saelens, L. Leary, K. Cain, T. L. Conway, and P.M. Hess. The Development of a Walkability Index: Application to the Neighborhood Quality of Life Study. British Journal of Sports Medicine, Vol. 44, No. 13, 2010, pp. 924-933. https://doi.org/10.1136 /bjsm.2009.058701.

2. Shay, E., S.C. Spoon, and A.J. Khattak. Walkable Environments and Walking Activity. Final report. Southeastern Transportation Center, University of Tennessee, Knoxville, 2003.

3. Marsden, G. The Evidence Base for Parking Policies-A Review. Transport Policy, Vol. 13, No. 6, 2006, pp. 447-457. https://doi.org/10.1016 /j.tranpol.2006.05.009.

4. Duncan, D., J. Aldstadt, J. Whalen, and S. Melly. Validation of Walk Scores and Transit Scores for Estimating Neighborhood Walkability and Transit Availability: A Small-Area Analysis. GeoJournal, Vol. 78, No. 2, 2013, pp. 407-416. https://doi.org/10.1007/s10708-011-9444-4.

5. Walk Score Methodology. https://www.walkscore.com/methodology .shtml.

6. Carr, L., S. Dunsiger, and B. Marcus. Walk Score ${ }^{\mathrm{TM}}$ as a Global Estimate of Neighborhood Walkability. American Journal of Preventive Medicine, Vol. 39, No. 5, 2010, pp. 460-463. https://doi.org/10.1016 /j.amepre.2010.07.007. 
7. Lwin, K., and Y. Murayama. Modelling of Urban Green Space Walkability: Eco-Friendly Walk Score Calculator. Computers, Environment and Urban Systems, Vol. 35, No. 5, 2011, pp. 408-420. https://doi.org /10.1016/j.compenvurbsys.2011.05.002.

8. Lee, I., and D. Buchner. The Importance of Walking to Public Health. Medicine and Science in Sports and Exercise, Vol. 40, No. 7 (Suppl.), 2008, pp. S512-S518.

9. Heath, G., R. Brownson, J. Kruger, R. Miles, K. Powell, and L. Ramsey. The Effectiveness of Urban Design and Land Use and Transport Policies and Practices to Increase Physical Activity: A Systematic Review. Journal of Physical Activity and Health, Vol. 3, Suppl. 1, 2006, pp. S55-S76. https://doi.org/10.1123/jpah.3.s1.s55.

10. Powell, K., and S. Blair. The Public Health Burdens of Sedentary Living Habits: Theoretical but Realistic Estimates. Medicine and Science in Sports and Exercise, Vol. 26, No. 7, 1994, pp. 851-856. https://doi.org /10.1249/00005768-199407000-00007.

11. Chastin, S., N. Fitzpatrick, M. Andrews, and N. DiCroce. Determinants of Sedentary Behavior, Motivation, Barriers, and Strategies to Reduce Sitting Time in Older Women: A Qualitative Investigation. International Journal of Environmental Research and Public Health, Vol. 11, No. 1, 2014, pp. 773-791. https://doi.org/10.3390/ijerph110100773.

12. Frank, L., J. Sallis, T. Conway, J. Chapman, B. Saelens, and W. Bachman. Many Pathways from Land Use to Health: Associations Between Neighborhood Walkability and Active Transportation, Body Mass Index, and Air Quality. Journal of the American Planning Association, Vol. 72, No. 1, 2006, pp. 75-87. https://doi.org/10.1080/01944360608976725.

13. Filion, P. Metropolitan Planning Objectives and Implementation Constraints: Planning in a Post-Fordist and Postmodern Age. Environment and Planning A, Vol. 28, No. 9, 1996, pp. 1637-1660. https://doi.org /10.1068/a281637.

14. Norman, J., H. MacLean, and C. Kennedy. Comparing High and Low Residential Density: Life-Cycle Analysis of Energy Use and Greenhouse Gas Emissions. Journal of Urban Planning and Development, Vol. 132, No. 1, 2006, pp. 10-21. https://doi.org/10.1061/(ASCE)0733-9488 (2006)132:1(10).

15. Burchell, R. W., N.A. Shad, D. Listokin, H. Phillips, A. Downs, S. Seskin, J.S. Davis, T. Moore, D. Helton, and M. Gall. TCRP Report 39: The Costs of Sprawl_Revisited. TRB, National Research Council, Washington, D.C., 1998.

16. Jilcott Pitts, S., J. McGuirt, L. Carr, Q. Wu, and T. Keyserling. Associations Between Body Mass Index, Shopping Behaviors, Amenity Density, and Characteristics of the Neighborhood Food Environment Among Female Adult Supplemental Nutrition Assistance Program (SNAP) Participants in Eastern North Carolina. Ecology of Food and Nutrition, Vol. 51, No. 6, 2012, pp. 526-541. https://doi.org/10.1080/03670244 2012.705749.

17. Chiu, M., B. Shah, L. Maclagan, M. Rezai, P. Austin, and J. Tu. Walk Score $^{\circledR}$ and the Prevalence of Utilitarian Walking and Obesity Among Ontario Adults: A Cross-Sectional Study. Health Reports, Vol. 26, No. 7, 2015, pp. 3-10.

18. Brown, S., H. Pantin, J. Lombard, M. Toro, S. Huang, E. Plater-Zyberk, T. Perrino, G. Perez-Gomez, L. Barrera-Allen, and J. Szapocznik. Walk Score ${ }^{\circledR}$ : Associations with Purposive Walking in Recent Cuban Immigrants. American Journal of Preventive Medicine, Vol. 45, No. 2, 2013, pp. 202-206. https://doi.org/10.1016/j.amepre.2013.03.021.

19. Liu, C., S. Erdogan, T. Ma, and F. W. Ducca. How to Increase Rail Ridership in Maryland? Direct Ridership Models (DRM) for Policy Guidance. Presented at 93th Annual Meeting of the Transportation Research Board, Washington, D.C., 2014.

20. Rakha, T., and C. Reinhart. A Carbon Impact Simulation-Based Framework for Land Use Planning and Non-Motorized Travel Behavior Interactions. In Proceedings of the 13th Conference of the International Building Performance Simulation Association, 2013, pp. 1248-1255.

21. Duncan, D., J. Aldstadt, J. Whalen, S. Melly, and S. Gortmaker. Validation of Walk Score ${ }^{\circledast}$ for Estimating Neighborhood Walkability: An Analysis of Four US Metropolitan Areas. International Journal of Environmental Research and Public Health, Vol. 8, No. 12, 2011, pp. 4160-4179. https://doi.org/10.3390/ijerph8114160.

22. Koschinsky, J., E. Talen, M. Alfonzo, and S. Lee. How Walkable Is Walker's Paradise? Environment and Planning B: Urban Analytics and City Science, Vol. 44, No. 2, 2017, pp. 343-363.

23. Weinberger, R., and M. N. Sweet. Integrating Walkability into Planning Practice. Transportation Research Record: Journal of the Transporta- tion Research Board, No. 2322, 2012, pp. 20-30. https://doi.org/10.3141 12322-03.

24. Fichier de Déplacements des Personnes dans la Région de Montréal Enquête Origine-Destination 2013. Agence Metropolitaine de Transport, Montreal, Quebec, Canada, 2013.

25. Chapleau, R. Conducting Telephone Origin-Destination Household Surveys with an Integrated Informational Approach. In Proceedings of the International Conference on Transport Survey Quality and Innovation, Transportation Research Board, Washington, D.C., 1997.

26. Manaugh, K., and A. El-Geneidy. What Makes Travel 'Local': Defining and Understanding Local Travel Behaviour. Journal of Transport and Land Use, Vol. 5, No. 3, 2012, pp. 15-27.

27. Winters, M., C. Voss, M.C. Ashe, K. Gutteridge, H. McKay, and J. Sims-Gould. Where Do They Go and How Do They Get There? Older Adults' Travel Behaviour in a Highly Walkable Environment. Social Science and Medicine, Vol. 133, 2015, pp. 304-312. https://doi.org /10.1016/j.socscimed.2014.07.006.

28. Clutter Data. DMTI Spatial, Inc., Markham, Ontario, Canada, 2005.

29. Canopée. Ville de Montréal, Montréal, Quebec, Canada, 2007.

30. Onishi, A., X. Cao, T. Ito, F. Shi, and H. Imura. Evaluating the Potential for Urban Heat-Island Mitigation by Greening Parking Lots. Urban Forestry and Urban Greening, Vol. 9, No. 4, 2010, pp. 323-332. https:// doi.org/10.1016/j.ufug.2010.06.002.

31. Shoup, D. The High Cost of Free Parking. Journal of Planning Education and Research, Vol. 17, No. 1, 1997, pp. 3-20. https://doi.org /10.1177/0739456X9701700102.

32. Zhu, X., and C. Lee. Correlates of Walking to School and Implications for Public Policies: Survey Results from Parents of Elementary School Children in Austin, Texas. Journal of Public Health Policy, Vol. 30, No. S1, 2009, pp. S177-S202. https://doi.org/10.1057/jphp.2008.51.

33. Manaugh, K., and A. El-Geneidy. Validating Walkability Indices: How Do Different Households Respond to the Walkability of Their Neighborhood? Transportation Research Part D: Transport and Environment, Vol. 16, No. 4, 2011, pp. 309-315. https://doi.org/10.1016/j.trd.2011 .01 .009 .

34. Heisz, A., and G. Schellenberg. Public Transit Use Among Immigrants. Canadian Journal of Urban Research, Vol. 13, No. 1, 2004, pp. 170-191.

35. O'Brien, R. A Caution Regarding Rules of Thumb for Variance Inflation Factors. Quality and Quantity, Vol. 41, No. 5, 2007, pp. 673-690. https://doi.org/10.1007/s11135-006-9018-6.

36. Leslie, E., N. Coffee, L. Frank, N. Owen, A. Bauman, and G. Hugo. Walkability of Local Communities: Using Geographic Information Systems to Objectively Assess Relevant Environmental Attributes. Health and Place, Vol. 13, No. 1, 2007, pp. 111-122. https://doi.org /10.1016/j.healthplace.2005.11.001.

37. Leigh, N., and N. Hoelzel. Smart Growth's Blind Side: Sustainable Cities Need Productive Urban Industrial Land. Journal of the American Planning Association, Vol. 78, No. 1, 2012, pp. 87-103. https://doi.org /10.1080/01944363.2011.645274

38. Ukkusuri, S., L. Miranda-Moreno, G. Ramadurai, and J. Isa-Tavarez. The Role of Built Environment on Pedestrian Crash Frequency. Safety Science, Vol. 50, No. 4, 2012, pp. 1141-1151. https://doi.org/10.1016 /j.ssci.2011.09.012.

39. Forsyth, A., M. Hearst, J. M. Oakes, and K. Schmitz. Design and Destinations: Factors Influencing Walking and Total Physical Activity. Urban Studies (Edinburgh, Scotland), Vol. 45, No. 9, 2008, pp. 1973-1996. https://doi.org/10.1177/0042098008093386.

40. Litman, T.A. Economic Value of Walkability. Transportation Research Record: Journal of the Transportation Research Board, No. 1828, 2003 , pp. 3-11. http://dx.doi.org/10.3141/1828-01.

41. Ewing, R., and S. Handy. Measuring the Unmeasurable: Urban Design Qualities Related to Walkability. Journal of Urban Design, Vol. 14, No. 1, 2009, pp. 65-84. https://doi.org/10.1080/13574800802451155.

42. Hart, M., and D. Sailor. Quantifying the Influence of Land-Use and Surface Characteristics on Spatial Variability in the Urban Heat Island. Theoretical and Applied Climatology, Vol. 95, No. 3-4, 2009, pp. 397-406. https://doi.org/10.1007/s00704-008-0017-5.

43. Solecki, W., C. Rosenzweig, L. Parshall, G. Pope, M. Clark, J. Cox, and M. Wiencke. Mitigation of the Heat Island Effect in Urban New Jersey. Global Environmental Change Part B: Environmental Hazards, Vol. 6, No. 1, 2005, pp. 39-49.

The Standing Committee on Pedestrians peer-reviewed this paper. 